\title{
ФОРМИРОВАНИЕ И ЭФФЕКТИВНОСТЬ ФУНКЦИОНИРОВАНИЯ ЭКОНОМИЧЕСКОГО ПОТЕНЦИАЛА РЕГИОНОВ СЕВЕРО-КАВКАЗСКОГО ФЕДЕРАЛЬНОГО ОКРУГА
}

\section{FORMATION AND EFFICIENCY OF THE ECONOMIC POTENTIAL OF THE REGIONS OF THE NORTH CAUCASUS FEDERAL DISTRICT}

\section{Muratova \\ A. Demyanenko}

Summary. In the aspect of regional socio-economic development, a fundamental role is played by the factor of effective use of the region's potential, which determines the need for new research and development in the aspect of assessing the potential of regional development. The research aims to assess the level of development potential of the regions of the North Caucasus Federal district, to characterize the degree of efficiency of its use, to identify features and patterns of socio-economic development of the regions, to search for and implement methodological approaches to objectively assess the development potential, and to identify priority areas for their further development.

Keywords: potential, North Caucasus, economy, development.

\author{
Муратова Людмила Ивановна \\ Д.э.н., професссор, ЧОУ ВО «Ессентукский институт \\ управления, бизнеса и права» \\ gbabkov@mail.ru \\ Демьяненко Андрей Евгеньевич \\ К.э.н., дочент, Северо-Кавказский институт \\ (филиал) АНО ВО «Московский гуманитарно- \\ экономический университет» \\ deanev4@gmail.com
}

Аннотация. В аспекте регионального социально-экономического развития основополагающую роль играет фактор эффективности использования потенциала региона, что предопределяет необходимость все новых исследований и разработок в аспекте оценки потенциала развития регионов. Проведенное исследование преследует цель осуществить оценку уровня потенциала развития регионов СевероКавказского федерального округа, охарактеризовать степень эффективности его использования, выявить особенности и закономерности социально-экономического развития регионов, поиск и реализацию методических подходов объективной оценки потенциала развития, определение приоритетных направлений их дальнейшего развития.

Ключевые слова: потенциал, СевероКавказский, экономика, развитие.

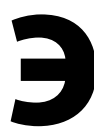
ффективное использование потенциала развития, достижение в регионах экономического роста, обеспечивающего более полное удовлетворение материальных и духовных потребностей населения возможны только при эффективной специализации и комплексном развитии социально-экономических систем регионов [1].

Экономическое развитие - это дуальный процесс расширенного воспроизводства, характеризующийся, с одной стороны, экономическим ростом, а с другой качественными и структурными изменениями, приводящими к большему и лучшему обеспечению возрастающих потребностей населения, к сбалансированной равновесной взаимосвязи предложения и спроса [2].

В настоящее время развитие региональной экономики требует активного поиска новых подходов и методов, а также средств оценки реформирования сложившейся ситуации [3].
Социально-экономическое развитие любой региональной системы определяется множеством факторов наличного и создаваемого характера, что образует специфические особенности текущего положения региональной системы [4].

Регионы Российской Федерации кардинально разнятся между собой по социально-экономическим характеристикам. Анализ, проведенный по регионам, входящим в Северо-Кавказский федеральный округ (СКФО), дал возможность выявить специфические особенности присущие данным регионам, а также закономерности социально-экономического развития исследуемых регионов.

Анализ социально-экономического развития региональных экономик предопределяет выбор соответствующего инструментария и методологии проведения исследования, которая в своем поэтапном процессе требует последовательного выполнения действий (опе- 
Таблица 1. Социальные характеристики регионов Северо-Кавказского федерального округа, 2017 г. Social characteristics of regions of the North-Caucasus Federal District, 2017

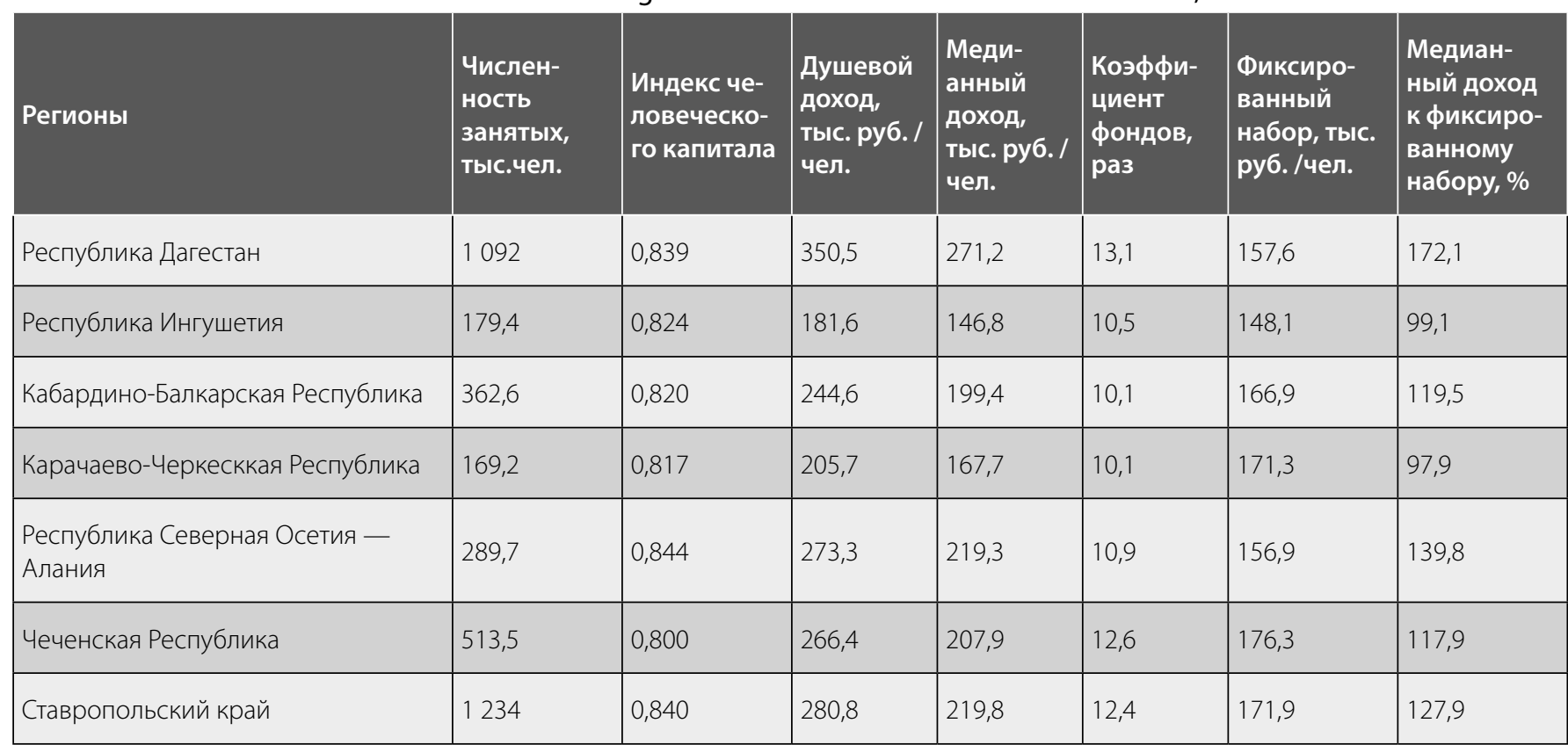

Авторское обобщение по данным Росстата [8, с. 19-21,190-191,220-221,1104-1107;10, с. 168-170]

раций), согласно разработанному алгоритму, обеспечивающему получение адекватных результатов, нацеленных на выявление имеющихся резервов региональных экономик и определение оптимальных путей их роста и развития.

Региональный менеджмент нацелен на повышение эффективности функционирования экономики региона, что достигается повышением эффективности использования потенциала развития [5]. Потенциал развития представляет собой имеющиеся возможности и резервы, которые, при определенном воздействии, при изменении условий, из потенциальных возможностей переходят в действительность [6].

Каждый регион обладает определенным потенциалом развития, и вариантов его использования - множество. При этом, добиваясь наиболее высоких результатов, необходимо выявлять оптимальные пути достижения ожидаемого результата, при максимизации уровня эффективности использования потенциальных возможностей [7].

Факторы регионального производства - различны. Они включают в себя материальные составляющие (основные фонды, инвестиции, финансы и т.д.), и нематериальные, выраженные например, информацией, предпринимательскими способностями населения и т.д. Факторы материального характера отождествлены количественными показателями, а вот нематериальные факторы регионального производства, могут быть выражены по косвенным признакам, например, по соотношению уровня индивидуальных предпринимателей и малого бизнеса к общей численности предприятий региона, либо же на основе экспертной оценки, например, инвестиционная привлекательность регионов.

Анализ, проведенный по регионам Северо-Кавказского федерального округа, позволяет выявить ряд специфических, закономерностей, тенденций и особенностей социально-экономического состояния и развития этих субъектов страны. Первая из них - специфическая динамика численности населения, включая, активное и занятое в экономике. [8, с. 40].

По республикам Дагестан, Ингушетия, Карачаево-Черкесской и Чеченской с 2005 г. по 2017 г. наблюдается, прежде всего, за счет естественного прироста, по существу последовательное увеличение численности населения, особенно по Чеченской Республике (с 1152 до 1437 тыс. чел.), тогда как по остальным регионам численность практически стабильна.

Как видно из таблицы 1, основные социальные характеристики по регионам Северо-Кавказского федерального округа также значительно разнятся.

По Республике Дагестан численность населения составляет 3052,9 тыс. чел., в том числе, занятых в экономике 1091,5 тыс. чел., соответственно, по Ставропольскому 
краю 2802,5 и 1233,7 тыс. чел., по Чеченской Республике 1425,9 и 513,5 тыс. чел.

Вместе с тем, по другим регионам численность населения колеблется от 865,1 тыс. чел. (в Кабардино-Балкарской Республике) до 466,4 тыс. чел. (в Карачаево-Черкесской Республике), а численность занятых в экономике, соответственно, составляет от 362,6 до 169,2 тыс. чел.

При этом, самый высокий уровень занятости населения характерен для Ставропольского края и Кабардино-Балкарской Республике (61,2\%), тогда как по Чеченской Республике и Республике Северная Осетия - Алания он составляет порядка 58\%, а по Карачаево-Черкесской Республике находится на уровне 52,8\%.

Важным показателем, характеризующим качество человеческого капитала, является соответствующий индекс, рассчитываемый Аналитическим Центром при Правительстве Российской Федерации [9, с. 168-170], в виде среднеарифметической интегральной характеристики частных индексов долголетия, образования и доходов населения (в сравнении с максимальными, ожидаемыми и минимальными значениями).

По регионам Северо-Кавказского федерального округа наблюдаются существенные различия по качеству человеческого капитала от 0,84 по Ставропольскому краю, Республикам Дагестан и Северная Осетия - Алания, до 0,82 по Республикам Ингушетия и Карачаево-Черкесской при характеристике 0,8 по Чеченской Республике.

Вторая особенность региональных экономик Северо-Кавказского федерального округа заключается в наблюдающейся корреляции между объемами валового регионального продукта, и соответствующими доходами населения. Самые низкие среднедушевые доходы за год наблюдаются по Республикам Ингушетия (181,6 тыс. руб.ччел.) и Карачаево-Черкесской Республике (205,7 тыс. руб. /чел.), где среднедушевые объемы ВРП (валового регионального продукта), за 2017 год, В соответствии с оценками Минэкономразвития [10, с. 108-110], составляли 288,4 и 461,6 тыс. руб./чел. Вместе с тем, самые высокие душевые доходы наблюдаются по Республике Дагестан и Ставропольскому краю (350,5 и 280,8 тыс. руб./чел.), коррелируя с большими по СКФО уровнями среднедушевого валового регионального продукта (574,9 и 562,7 тыс. руб./чел.).

Как видно из таблицы 1, разница между традиционным среднедушевым и медианным доходом значительна: по Республике Дагестан и Ставропольскому краю, соответственно, 350,5 и 280,8 тыс. руб./чел., 271,2 и 219,8 тыс. руб./чел.; а по Карачаево-Черкесской Респу- блике и Республике Ингушетия 205,7 и 181,6 тыс. руб./ чел., 167,7 и 146,8 тыс. руб./ чел.

Обычно, для характеристики уровня жизни населения используется соотношение среднедушевых доходов с прожиточным минимумом. Однако последний показатель свидетельствует, по существу, о нищете населения, ибо прожить, например, в Ставропольском крае на 8248 руб./чел. в месяц [8, с. 223-226], а пенсионеру на 6707 руб./чел. практически невозможно.

Соответствующие различия соотношения медианных доходов к фиксированному набору товаров и услуг составляют от 97,9\% по Карачаево-Черкесской Республике и 99,1\% по Республике Ингушетия до $172,1 \%$ по Республике Дагестан.

Третья специфическая особенность социальных характеристик регионов Северо-Кавказского федерального округа заключается в обратной корреляции между, с одной стороны, среднедушевыми объемами валового регионального продукта и доходов населения, с другой стороны, показателями расслоения населения по уровню жизни. Самые низкие параметры расслоения населения по их доходам, с позиций рассчитываемого в статистике коэффициента фондов [8, с. 220-221], наблюдаются в таких регионах, как Карачаево-Черкесская и Кабардино-Балкарская Республики, а также Республика Ингушетия (с самыми низкими доходами), где коэффициент фондов колеблется от 10,1 до 10,5 раз на фоне 12,4-13,1 раз по Ставропольскому краю, Чеченской Республике и Республике Дагестан (с более высокими доходами).

Значимыми движителями экономического развития, существенными элементами соответствующего потенциала, являются расходы на экономику национального и регионального бюджетов, денежные вклады юридических и физических лиц в банковской системе, сальдированный финансовый результат субъектов хозяйствования, и что не менее важно, объем потребительских расходов населения. Именно расходы населения через транслятор потребительской подсистемы региональной экономики, прежде всего торговли, финансируют и активируют своей покупательной способностью те или иные отрасли экономики и соответствующие виды экономической деятельности [11].

Совокупность объемов потребительских расходов населения, расходов регионов на экономику и жилищно-коммунальное хозяйство, прибыли субъектов хозяйствования, а также банковских вкладов (которые должны использоваться банковской системой для инвестирования не только виртуальной, но прежде всего реальной экономики) и инвестиций в основной капитал 
Таблица 2. Потребительско-инвестиционный портфель потенциала развития регионов Северо-

Кавказского федерального округа, 2017 г.

Consumer and investment portfolio of development potential of regions of the North-Caucasus Federal District, 2017

\begin{tabular}{|c|c|c|c|c|c|c|c|}
\hline \multirow[b]{2}{*}{ Регионы } & \multirow{2}{*}{$\begin{array}{l}\text { Потреби- } \\
\text { тельскоинве- } \\
\text { стиционный } \\
\text { портфель, } \\
\text { млрд. руб. }\end{array}$} & \multicolumn{5}{|c|}{ Структура портфеля,\% } & \multirow[b]{2}{*}{$\begin{array}{l}\text { Собствен } \\
\text { ные доходы } \\
\text { к бюджету } \\
\text { региона,\% }\end{array}$} \\
\hline & & $\begin{array}{l}\text { Объем } \\
\text { потреби- } \\
\text { тельских } \\
\text { рас ходов }\end{array}$ & $\begin{array}{l}\text { Расходы } \\
\text { региона }\end{array}$ & Вклады & $\begin{array}{l}\text { Сальдирован } \\
\text { ный финан- } \\
\text { совый ре } \\
\text { зультат }\end{array}$ & $\begin{array}{l}\text { Инве- } \\
\text { стиции в } \\
\text { основной } \\
\text { капитал }\end{array}$ & \\
\hline Республика Дагестан & 1155 & 76,3 & 1,8 & 3,6 & 1,0 & 17,3 & 31,4 \\
\hline Республика Ингушетия & 62 & 65,4 & 6,1 & 5,8 & 2,1 & 20,6 & 18,8 \\
\hline Кабардино-Балкарская Республика & 231 & 69,4 & 2,9 & 9,7 & 0,3 & 17,7 & 43,8 \\
\hline Карачаево-Черкесккая Республика & 89 & 59,1 & 6,4 & 13,5 & 1,0 & 20,0 & 34,6 \\
\hline $\begin{array}{l}\text { Республика Северная Осетия - } \\
\text { Алания }\end{array}$ & 203 & 70,5 & 2,5 & 13,6 & 0,2 & 13,2 & 50,5 \\
\hline Чеченская Республика & 297 & 72,1 & 3,1 & 1,4 & 2,4 & 21,0 & 19,7 \\
\hline Ставропольский край & 1058 & 64,2 & 2,3 & 15,7 & 4,6 & 13,2 & 69,9 \\
\hline
\end{tabular}

Авторские расчёты по данным Росстата [8, с. 230-231,487-488,974-987,1012-1019]

формирует совокупность - потребительско-инвестиционный портфель потенциала развития.

Как видно из таблицы 2, совокупный потребительско-инвестиционный портфель потенциала развития региональной экономики существенно разнится по регионам Северо-Кавказского федерального округа.

По данным 2017 г. совокупный потребительско-инвестиционный портфель потенциала развития региональной экономики составлял от 1155 млрд. руб. по Республике Дагестан и 1058 млрд. руб. по Ставропольскому краю до 297,2 млрд. руб. по Чеченской Республике, 230,8 млрд. руб. по Кабардино-Балкарской Республике и 203,2 млрд. руб. по Республике Северная Осетия-Алания при 89,2 млрд. руб. по Карачаево-Черкесской Республике и 62,4 млрд. руб. по Республике Ингушетия.

Как показывают расчеты, основным элементом потребительско-инвестиционного портфеля потенциала развития региональной экономики является объем потребительских расходов, являющихся в большей мере краткосрочным движителем экономики. Его доля колеблется от 59,1\% по Карачаево-Черкесской Республике и 64,2\% по Ставропольскому краю до 72,1\% по Чеченской Республике и 76,3\% по Республике Дагестан. В этом заключается четвертая специфическая особенность функционирования региональных экономик Северо-Кавказского федерального округа.

Значительный удельный вес в потребительско-инвестиционном портфеле потенциала развития региональной экономики составляют также инвестиции и банковские вклады, при существенных различиях по анализируемым субъектам Федерации.

Доля вкладов юридических и физических лиц превалирует по Ставропольскому краю (15,7\%), а также по Республикам Северная Осетия - Алания и Карачаево-Черкесской (13,6-13,5\%), тогда как инвестиции в основной капитал составляют больший удельный вес по Чеченской Республике (21\%), Республике Ингушетия (20,6\%) и Карачаево-Черкесской Республике (20\%), находятся на уровне 13,2\% по Ставропольскому краю и Республике Северная Осетия-Алания. Вместе с тем, очень низкой является доля вкладов по чеченской Республике $(1,4 \%)$, а также Республикам Дагестан и Ингушетия (3,6 и 5,8\%).

Все регионы Северо-Кавказского федерального округа, включая Ставропольский край, с позиций структуры их бюджетов, является реципиентами со значительным финансированием со стороны государства. Так, доля собственных доходов в региональных бюджетах 
Таблица 3. Группировка регионов Северо-Кавказского федерального округа по потенциалу развития, 2017 г.

Group of Regions of the North-Caucasus Federal District by Development Potential, 2017

\begin{tabular}{|c|c|c|c|}
\hline \multirow{3}{*}{ Показатели } & \multicolumn{3}{|c|}{ Группы регионов, баллы } \\
\hline & \multirow[b]{2}{*}{ до 95} & \multicolumn{2}{|c|}{ свыше 95} \\
\hline & & всего & $\begin{array}{l}\text { В т.ч. Ставропольский } \\
\text { край }\end{array}$ \\
\hline Потенциал развития, баллы & 28 & 101 & 107 \\
\hline Уровень занятости населения,\% & 57 & 58 & 61 \\
\hline Основные фонды, млрд. руб. & 282 & 1703 & 1777 \\
\hline Потребительско-инвестиционный портфель, млрд. руб. & 177 & 1107 & 1058 \\
\hline Оборот МП, млрд. руб. & 45 & 394 & 596 \\
\hline Условное топливо, тыс. Т & 2318 & 7144 & 8941 \\
\hline Инновационная продукция, млн. руб. & 195 & 16874 & 33567 \\
\hline Интегральный показатель специализации, баллы & 73 & 80 & 83 \\
\hline Затраты на ИКТ, млн. руб. & 721 & 2615 & 4324 \\
\hline Природно-ресурсный потенциал, ранги & 16 & 43 & 41 \\
\hline Доля регионов в бюджетной системе РФ,\% & 0,1 & 0,4 & 0,6 \\
\hline ВРП, млрд. руб. & 116 & 661 & 694 \\
\hline Использование потенциала, млрд. руб./балл & 4,2 & 6,5 & 6,5 \\
\hline
\end{tabular}

Авторские расчеты по данным Росстата

составляет по Чеченской Республике и Республике Ингушетия только 19,7\% и 18,8\%, по Республикам Дагестан и Карачаево-Черкесской 31,4 и 34,6\%, достигая только уровня 69,9\% по Ставропольскому краю. Таким образом, в настоящее время, не один из регионов Северо-Кавказского Федерального округа не имеет возможностей для самофинансирования.

Интегральная оценка различных показателей, свидетельствующих о многогранном характере специализации регионального производства, осуществляется с учётом их значимости в формировании валового регионального продукта (на основе вычисления частных коэффициентов детерминации).

Одним из базисных факторов экономического и развития являются предпринимательские способности населения, в большей мере проявляющиеся при функционировании малых предприятий (МП) и индивидуальных предпринимателей.

Судя по статистике, численность работников малого бизнеса, является самой высокой по Ставропольскому краю (138,3 тыс. чел.), а по другим регионам Северо-Кавказского федерального округа колеблется от 45,6 тыс. чел. по Республике Дагестан до 23-18,8 тыс. чел. по Чеченской Республике, Республике Северная Осетия-Алания и Кабардино-Балкарской Республике при самой низкой характеристике по Республике Ингушетия (3,7 тыс. чел.).

Расчет показателей производительности живого труда (по малым предприятиям и регионам в целом) позволяет выявить еще одну особенность (по существу закономерность), суть которой в существенно более высокой производительности живого труда в малом бизнесе, которая превышает соответствующие характеристики по регионам в 13,7 раза по Республике Ингушетия в 7,09 раза по Республике Дагестан и в 6,19 раза по Чеченской Республике.

При этом, соответствующие различия по другим регионам составляют от 4,51 раз по Кабардино-Балкарской Республике до 2,73 по Ставропольскому краю.

Ранги природно-ресурсного потенциала колеблются от 41 по Ставропольскому краю, 34 по Кабардино-Бал- 
карской Республике и 24 по Карачаево-Черкесской Республике до 12 по Чеченской Республике, 9 по Республике Северная Осетия-Алания и 3 по Республике Ингушетия [12].

Количественными характеристиками использования природно-ресурсного потенциала в региональных экономиках являются показатели экспорта продукции сырьевых отраслей (топливно-энергетического комплекса, химической, лесной и деревообрабатывающей промышленности, добычи металлов и металлообработки).

Важной характеристикой является доля природных ресурсов в общем экспорте региона, которая колеблется от 60,6\% по Карачаево-Черкесской Республике и 54,557,9\% по Ставропольскому краю, Республике Северная Осетия-Алания и Чеченской Республике до 18,3\% по Кабардино-Балкарской Республике и 16,2\% по Республике Ингушетия.

Расчеты показывают, что, наряду с абсолютными характеристиками, по регионам значительно разнятся характеристики износа основных фондов, составляющие в 2017 г. от 37,6\% по Карачаево-Черкесской Республике и 40,4\% по Кабардино-Балкарской Республике составлявшие, до 53,4-57\%, соответственно, по Ставропольскому краю, Республике Дагестан, Республике Северная Осетия-Алания и Чеченской Республике [8, c. 547-548].

Сравнительный анализ ключевых характеристик потенциала развития и валового регионального продукта, показывает их тесную взаимосвязь, в чем заключается очередная особенность развития регионов Северо-Кавказского федерального округа. Регионы с лучшими объективными возможностями производят, как правило, большие объемы товаров и услуг, тогда как в субъектах федерации с худшим потенциалом объемы ВРП (валового регионального продукта) ниже. О тесной связи потенциала развития с результатами хозяйственной деятельности регионов Северо-Кавказкого федерального округа наглядно свидетельствуют очень высокий коэффициент корреляции $(0,972)$, а также соответствующая аналитическая группировка (табл. 3).

Как видно из проведенных расчетов, увеличение характеристик объективных возможностей региональных экономик Северо-Кавказского федерального округа от 28 баллов в среднем по регионам первой группы, до 101 баллов по регионам второй группы (при 107 баллов по Ставропольскому краю) сопровождается последовательным ростом почти всех факторов производства, приводя к увеличению валового регионального продукта. Это свидетельствует, во-первых, о влиянии потенциа- ла развития на результаты хозяйственной деятельности анализируемых субъектов Федерации, а во-вторых, о направленности анализируемых регионов к многофакторному характеру осуществляемой интенсификации регионального производства.

На основании проведенного анализа можно сделать вывод о наблюдающемся многофакторном характере осуществляемой в анализируемых субъектах федерации интенсификации регионального производства с наблюдающимися доминантами развития, которыми, прежде всего, являются доступные экономике денежные средства, специализация и основные фонды.

Вместе с тем, между конкретными элементами потенциала развития также наблюдаются различные, зачастую существенные, характеристики тесноты связей, чем определяется необходимость расчета многофакторных зависимостей валового регионального продукта от анализируемых факторов производства.

Проведенный по регионам страны многофакторный экономико-математический анализ позволил, выявить значимость элементов потенциала развития в формировании валового регионального продукта с определением соответствующих коэффициентов регрессии по модели с абсолютными характеристиками и эластичности по модели с нормированными (к средним по РФ показателям) характеристиками.

Сортировка ключевых показателей анализируемых субъектов Федерации по оценке использования потенциала развития в две группы позволяет выявить, чем в основном можно объяснить наблюдающиеся различия в функционировании региональных экономик.

Анализ показал, что большая часть ключевых показателей имеет лучшие средние характеристики во второй группе регионов с лучшим потенциалом развития: по уровню занятости в экономике, объемам материально-технической базы, обороту малых предприятий, затратам на информационно-коммуникационные технологии, потребительско-инвестиционному портфелю и налоговым поступлениям, природно-ресурсному потенциалу и объемам условного топлива.

В этих условиях, главными причинами лучшей эффективности функционирования регионов второй группы являются, во-первых, большая концентрация разнообразных активов потенциала развития, во-вторых, углубление специализации производства региональной экономики, в третьих наличие больших денежных средств и, соответственно, большая интенсивность хозяйственной деятельности региональной экономики. 


\section{ЛИТЕРАТУРА}

1. Исянбаев М. Н. Стратегия развития территориальных социально-экономических систем региона: приоритетные направления, механизмы реализации // Проблемы востоковедения. 2018. № 3 (81). С. 21-26.

2. Алексеев А.В., Кузнецова И. В. Сравнительная характеристика методик оценки уровня социально-экономического развития региональной социально-экономической системы // Новые технологии. 2018. № 2. С. 73-79.

3. Волков А.А., Зайцев А. Г., Такмакова Е. В. Определение приоритетов развития региона на основе экономико-математического моделирования его экономического потенциала // Региональная экономика: теория и практика. 2015. № 37 (412). С. 34-43.

4. Карташов К.А., Прудникова М. В. Социально-экономическое развитие региональной системы // Концепт. 2017. № S4. URL: https://cyberleninka.ru/article/n/ sotsialno-ekonomicheskoe-razvitie-regionalnoy-sistemy (дата обращения: 19.09.2019).

5. Разуваев В. В. Методика оценки научно-технического потенциала регионов Российской Федерации // Вестник ПГу. Серия: Экономика. 2012 . № 3. С. 66-74.

6. Репова М.Л., Лобанова Ю.С. Исследование тенденций развития региональных социально-экономических систем // Финансовая аналитика: проблемы и решения. 2015. № 15 (249). С. 32-41.

7. Морковкин Д. Е. Социально-экономические аспекты устойчивого развития экономики территорий // Вестник Московского университета имени С. Ю. Витте. Серия 1: Экономика и управление. 2014. № 1 (7). С. 4-11.

8. Регионы России. Социально-экономические показатели.-М.: Росстат, 2018. 1164 с.

9. Человек и инновации. Доклад о человеческом развитии Российской Федерации за 2018 год. /под ред. С. Н. Бобылева, Л. М. Григорьева — М.: АЦПРФ, 2018. 172 c.

10. Государственный доклад о состоянии энергосбережения и повышении энергетической эффективности в Российской Федерации в 2017 году.— М.: Минэкономразвития, 2018. С. 108-110.

11. Финансы России. - М.: Росстат, 2018.

12. Рейтинг инвестиционной привлекательности регионов России. - М.: raex-a.ru [электронный ресурс]. URL: https://delen.ru/investicii/rejting-regionov-poinvesticionnoj-privlekatelnosti.html (дата обращения 23 сентября 2019 г.).

○ Муратова Людмила Ивановна ( gbabkov@mail.ru ), Демьяненко Андрей Евгеньевич ( deanev4@gmail.com ).

Журнал «Современная наука: актуальные проблемы теории и практики»

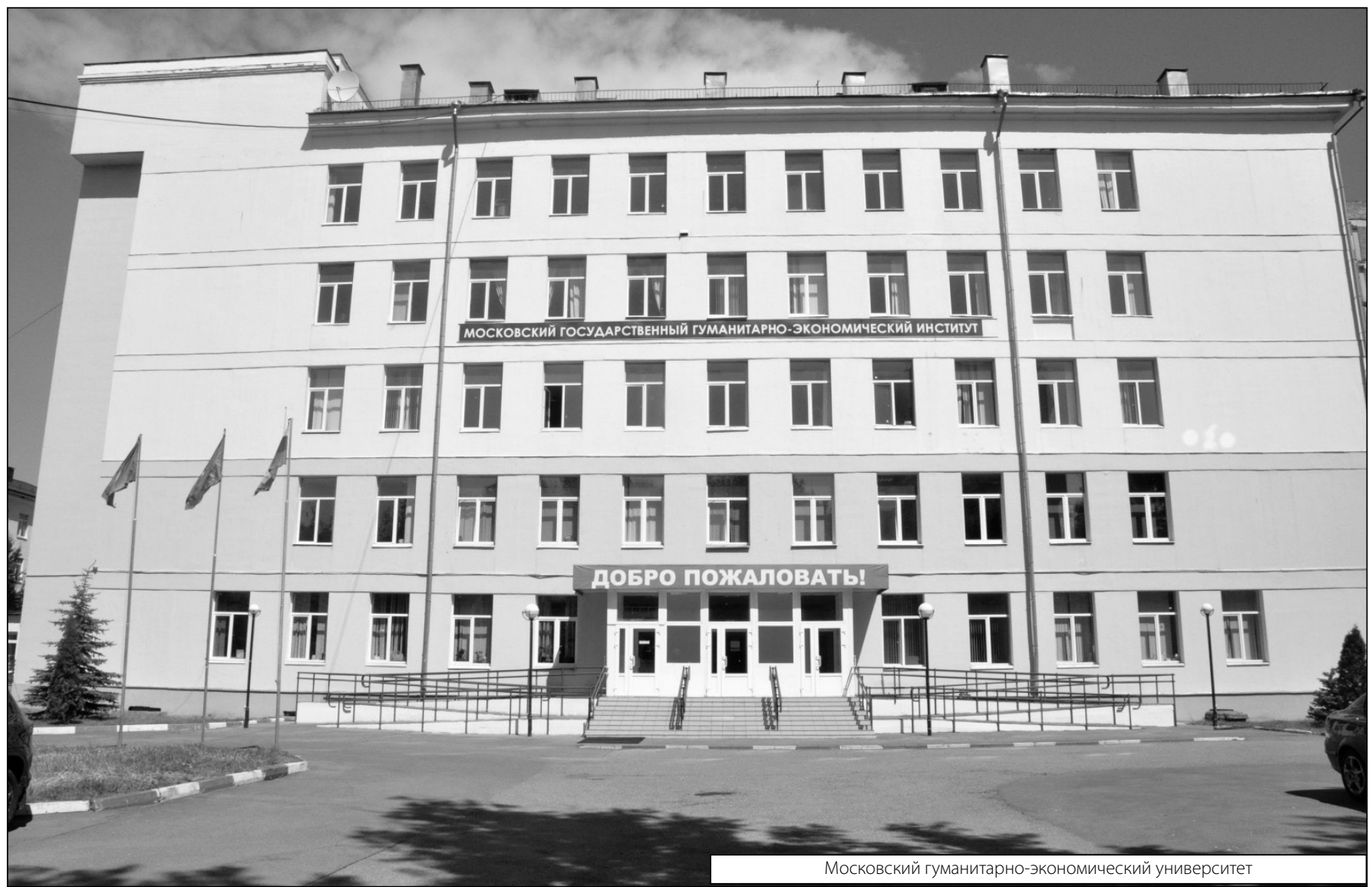

